\title{
Effects of varying doses of tramadol on ketamine anaesthesia for laparocaecectomy in layer chickens
}

\author{
Oghenemega David Eyarefe and Cecilia O. Oguntoye* \\ Department of Veterinary Surgery and Reproduction, Faculty of Veterinary Medicine, University of Ibadan, \\ Oyo State, Nigeria.
}

Received 21 August 2015; Accepted 16 November, 2015

\begin{abstract}
The effects of a high ketamine dose $(15 \mathrm{mg} / \mathrm{kg})$ and a low ketamine dose $(10 \mathrm{mg} / \mathrm{kg})$ combined with two separate doses of tramadol (10 and $5 \mathrm{mg} / \mathrm{kg}$ ) were studied in chickens. Seventeen layer chickens (Isa brown breed) presented for laparo-cecectomy associated with feed trials were randomized into Ketamine-Lignocaine (KL) group (15 mg/kg ketamine)- 5 chickens, Tramadol-Ketamine-Lignocaine (TKL) group (10 mg ketamine plus $5 \mathrm{mg} / \mathrm{kg}$ tramadol)- 5 chickens and Tramadol-2-Ketamine-Lignocaine (TTKL) group (10 mg ketamine plus $10 \mathrm{mg} / \mathrm{kg}$ tramadol)- 7 chickens. All chickens had $2 \%$ lignocaine incision site infiltration to provide additional analgesia. Onset of drug action (OAN), Duration of recumbency (DR), heart rates (HR), respiratory rates (RR) and cloacal temperature (CT) were evaluated as anaesthetic monitoring indices. The trend for OAN was $K L(3.3 \pm 0.4 \mathrm{~min})>T K L$ group $(4.0 \pm 3.0 \mathrm{~min})>$ TTKL group $(8.2 \pm 2.5 \mathrm{~min})$. DR was $\mathrm{KL}$ group $(110.3 \pm 20.8 \mathrm{~min})>$ TTKL group $(81.2 \pm 5.5 \mathrm{~min})>\mathrm{TKL}$ group (62.6 $\pm 4.7 \mathrm{~min})$. The mean variation of pre-anaesthetic and anaesthetic values of HR was not significant, although the $K L$ group had the lowest HR. Observed fall in RR with TTKL $<T K L<K L$ was not significant $(P>0.05)$ among the groups. A statistically none significant $(P>0.05)$, none life threatening fall in temperature was also observed among the groups. In the absence of inhalatory anaesthesia, $10 \mathrm{mg} / \mathrm{kg}$ ketamine combined with tramadol $(5-10 \mathrm{mg} / \mathrm{kg})$ and lignocaine infiltration may be a preferred anaesthetic protocol for non-protracted surgical procedures in chickens.
\end{abstract}

Key words: Anaesthesia, ketamine, layer chickens, lignocaine, tramadol.

\section{INTRODUCTION}

Injectable anaesthesia continues to be in common use for avian practice in many African and Asian countries due to high cost of delivery apparatus for inhalation anaesthesia (Curro, 1998; Eyarefe and Oguntoye, 2012). Although few disadvantages such as, risk of overdosing in small birds, difficulty in maintaining surgical anaesthesia without severe cardiopulmonary depression and prolonged recovery have been identified (Franchetti and Klide, 1978; Paul-Murphy and Fialkowski, 2001; Ludders, 2015), injectable anaesthesia continues to be in use due to minimal equipment need, low cost, quick anaesthetic induction, as well as, minimal or no pollution of work environment (Paul-Murphy and Fialkowski, 2001; Gandomani et al., 2009; Ludders, 2015). Injectable

*Corresponding author. E-mail: wumcel06@gmail.com.

Author(s) agree that this article remain permanently open access under the terms of the Creative Commons Attribution License 4.0 International License 
anaesthetic agents are frequently employed for minor surgical procedures in medium and large sized birds, for chemical restraint and as induction agents prior to inhalatory anaesthesia (Girling, 2009; Forbes, 1999; Flecknell, 2009). Severe cardiopulmonary depression, as well as, prolonged and violent recovery has precluded the use of single agents for surgical anaesthesia, thereby encouraging research into possible drugs combinations (Forbes, 1999; Ludders, 2015). The need for understanding of species specific pharmacokinetics and pharmacodynamic profile of each injectable drug has also been emphasized (Hawkins and Paul-Murphy, 2011).

Ketamine is a useful drug in avian practice and recommended for use in a wide range of avian species (Flecknell, 2009). When used alone, it is suitable for chemical restraint for minor surgical and diagnostic procedures (Ludders and Matthews, 2007). However, it is not a suitable general anaesthetic agent for major surgical manipulations (Ludders and Mathews, 2007) as high doses in birds are characterized by cardiopulmonary depressant effects and prolong recovery (Flecknell, 2009; Ludders, 2015). Therefore, combining ketamine with other injectable agents to allow for reduction of dose and faster recovery has been suggested in literature (Curro, 1998; Forbes, 1999; Edling, 2006; Uzma et al., 2008). Ketamine (20 to $40 \mathrm{mg} / \mathrm{kg}$ ) combined with diazepam (1$1.5 \mathrm{mg} / \mathrm{kg}$ ), provided adequate chemical restraint with excellent muscle relaxation, but no additional analgesia as compared to that provided by ketamine (Curro, 1998; Ludders and Mathews, 2007) which make the combination unsuitable for major manipulative procedures. Ketamine has also been combined with $\alpha 2$ agonist drugs (xylazine and medetomidine). Its combination with xylazine reduced the dosage, enhanced sedation and analgesia and improved recovery rates (Girling, 2009; Divers, 2014). However, this combination is less popular because it produces severe cardiac and respiratory suppressant effects (Divers, 2014), and thus should be used with caution, especially, in debilitated birds (Girling, 2009).

Opiods-ketamine combination has also been reported in literature (Divers, 2014). Ketamine-butorphanol combination has been tried and the combination prized for its good visceral analgesia for which ketamine alone is weak (Sawyer et al., 1993; Lamont et al., 2000). However, the routine use of butorphanol is limited in most countries due to strict regulation and high cost (Ajadi et al., 2009; Egger et al., 2009).

Tramadol is a synthetic analogue of codeine (BorerWeir, 2014), and is less expensive, less restricted and more readily available in poor resource settings (Ajadi et al., 2009). It is a centrally acting opiate analgesic that has not been well studied in avian species. Tramadol and its metabolites exert their effects at multiple sites, including opiate $(\mu, \mathrm{K}$, and $\delta)$, adrenergic $(\alpha-2)$ and serotonin $(5 \mathrm{HT})$ receptors (Black et al., 2010). This multi-receptor mode of action which is lacking in other opiates (Paul-Murphy and Fialkowski, 2001) makes tramadol a potentially useful analgesic in avian practice. Few studies on tramadol in birds (Souza et al., 2009, 2012; Javdani et al., 2012, 2014) suggest an effective analgesic potential and a possibility of balanced anaesthesia when combined with ketamine. In a previous study (Eyarefe and Oguntoye, 2012), $15 \mathrm{mg} / \mathrm{kg}$ ketamine with incisional site lignocaine infiltration for laparocaecectomy in layer chicken produced a moderate to severe cardiac depression (mean heart rate ranged from $149.1 \pm 7.6$ to $189.7 \pm 9.5$ min), and prolonged but smooth recovery. In this study, it was hypothesized that tramadol in combination with a lower dose of ketamine will produce a more effective injectable anaesthestic protocol with a shorter recovery period for chickens. Therefore, this study aimed at evaluating and comparing the effects of two doses (5 and $10 \mathrm{mg} / \mathrm{kg}$ ) of tramadol on a lower dose of ketamine (10 $\mathrm{mg} / \mathrm{kg}$ ) for laparocaecetomy in layer chickens.

\section{MATERIALS AND METHODS}

\begin{abstract}
Animals
Seventeen (17) clinically healthy layer chickens (Isa Brown), aged 26 weeks with mean body weight of $1.43 \pm 0.03 \mathrm{~kg}$ were used. The chickens, which were to be involved in a nutritional trial, were presented to the Surgery Clinic of the Veterinary Teaching Hospital, University of Ibadan, for caecectomy.
\end{abstract}

\section{Housing}

The chickens were housed in the Teaching and Research Farm of the University of Ibadan, Ibadan, Nigeria in well ventilated cages and provided with a compounded layer's ration and water ad libitum. The study protocol was approved by the faculty ethical committee for the use of animals for research.

\section{Study protocol}

\section{Anaesthesia}

The chickens were randomized into three groups designated as $\mathrm{KL}$ (5 chickens TKL (5 chickens) and TTKL (7 chickens). Feed was withdrawn on the morning of the trials but the birds had access to water till $1 \mathrm{~h}$ before anaesthetic drug administration. The chickens in the TTKL group were given $10 \mathrm{mg} / \mathrm{kg}$ body weight of tramadol (Non-proprietary, Eurolife PVT Ltd, India) followed immediately by administration of $10 \mathrm{mg} / \mathrm{kg}$ body weight of ketamine hydrochloride (Ketamine; Rotex Medica, Germany) while the TKL group of chickens had $5 \mathrm{mg} / \mathrm{kg}$ body weight of tramadol followed by immediate administration of $10 \mathrm{mg} / \mathrm{kg}$ body weight of ketamine. The $\mathrm{KL}$ group of chickens was given $15 \mathrm{mg} / \mathrm{kg}$ body weight of ketamine only. All the drugs were administered intramuscularly at the quadriceps group of muscles. Following loss of the righting reflex, the surgical site was aseptically prepared and $2 \mathrm{ml}$ lignocaine hydrochloride (Glocain, Vital Health Care PC Ltd, India, 2\%) was administered subcutaneously at the site of incision which was midline of their ventral abdomen. Laparo-caecectomy was then performed. The depth of anaesthesia was determined by lack of response of the birds to skin or bowel manipulation. 
Table 1. Anesthetic indices of chickens in response to intramuscular injections of $15 \mathrm{mg} / \mathrm{kg}$ ketamine (KL), and $10 \mathrm{mg} / \mathrm{kg}$ ketamine following either $5 \mathrm{mg} / \mathrm{kg}$ (TKL) or $10 \mathrm{mg} / \mathrm{kg}$ (TTKL) tramadol.

\begin{tabular}{lccc}
\hline Indices & TKL & TTKL & KL \\
\hline Onset of action/analgesia (in minutes) & $4.0 \pm 3.0$ & $8.2 \pm 2.5$ & $3.3 \pm 0.4$ \\
Duration of recumbency (in minutes) & $62.6 \pm 4.7$ & $81.2 \pm 5.5$ & $110.3 \pm 20.8$ \\
\hline
\end{tabular}

\section{Anaesthetic indices}

The onset of drug action was determined as the time interval in minutes between the administration of ketamine and the loss of the righting reflex by the chickens. Duration of recumbency was determined by the time interval (in minutes) between the loss of righting reflex and the ability of the chickens to stand following surgery.

\section{Measured physiological parameters}

In the course of each trial, heart rates $(H R)$, respiratory rates $(R R)$ and rectal temperature (RT) were determined before drug administration (time 0 ), immediately after the loss of righting reflex (time $0_{1}$ ) and thereafter, at 10 min intervals over the first $60 \mathrm{~min}$ of anaesthesia. Heart rate (in beats/min) was determined with the aid of a precordial stethoscope placed over the left second and fifth intercostal spaces, respiratory rate (in breaths $/ \mathrm{min}$ ) was determined by observation of the chickens' thoracic excursions and cloacal temperature $\left({ }^{\circ} \mathrm{C}\right)$ was determined using a mercury-in-glass clinical thermometer.

\section{Data analysis}

All data were expressed as mean \pm standard error of mean (SEM). Mean values of anaesthetic indices were compared using student $t$ test for paired data. Analysis of variance (ANOVA) with repeated measures was used to detect the significant differences of mean values of HR, RR and CT from baseline. Dunnet's test was used to detect the time at which treatment response differed from the baseline. A value of $p<0.05$ was considered significant.

\section{RESULTS}

\section{Birds' behaviour}

Following administration of anaesthetic drug, each chicken paced up and down, sat down and later rested on the keel (breast bone), before finally turning over on its side, and stretched out the legs (Plates 1,2 and 3). They closed their eyes for a short period and later opened them (Plate 4). Wing clapping was inconsistent among the groups.

\section{Onset of drug action}

The onset of drug action was shortest in the $\mathrm{KL}$ group, intermediate in the TKL group and longest in the TTKL group (Table 1).

\section{Duration of recumbency}

Duration of recumbency was longest in the chickens in the $\mathrm{KL}$ group, intermediate with those in the TTKL group and shortest with the TKL group (Table 1).

\section{Effects of trial on heart rate}

The mean heart rates of the chickens under the influence of the three anaesthetic protocols are shown in Figure 1. The values of this parameter remained fairly constant when compared with the pre anaesthetic values in all the chickens except for the KL group of chickens that had a slight fall in heart rate.

\section{Effects of trial on respiratory rate}

There were no significant ( $p>0.05)$ changes in the respiratory rates of the chickens in the $\mathrm{KL}$ group when compared with the pre anaesthetic values. A slight $(P>0.05)$ fall in rates was observed in the TKL and TTKL groups with the TTKL being more pronounced (Figure 2).

\section{Effects of trial on cloacal temperature}

A non-significant $(P>0.05)$ decrease in temperature was observed in all the groups within the period of the trial (Figure 3).

\section{Cost of anaesthetic protocol for each group}

The average total cost of the drugs used per bird for each anaesthetic protocol is 35.46 (0.16 USD); 30.46 (0.14 USD) and 34.03 (0.16 USD) for the KL, TKL and TTKL groups, respectively (Table 2 ).

\section{DISCUSSION}

The need for investigation into easier, safer and cost effective anaesthetic and analgesic protocol for minor surgical procedures in chickens and exotic birds continue to resurge. In recent years, interest in conservation of wild life has led to an increased demand for aneasthesia for surgical purposes in wild or semi-wild birds, as well, 


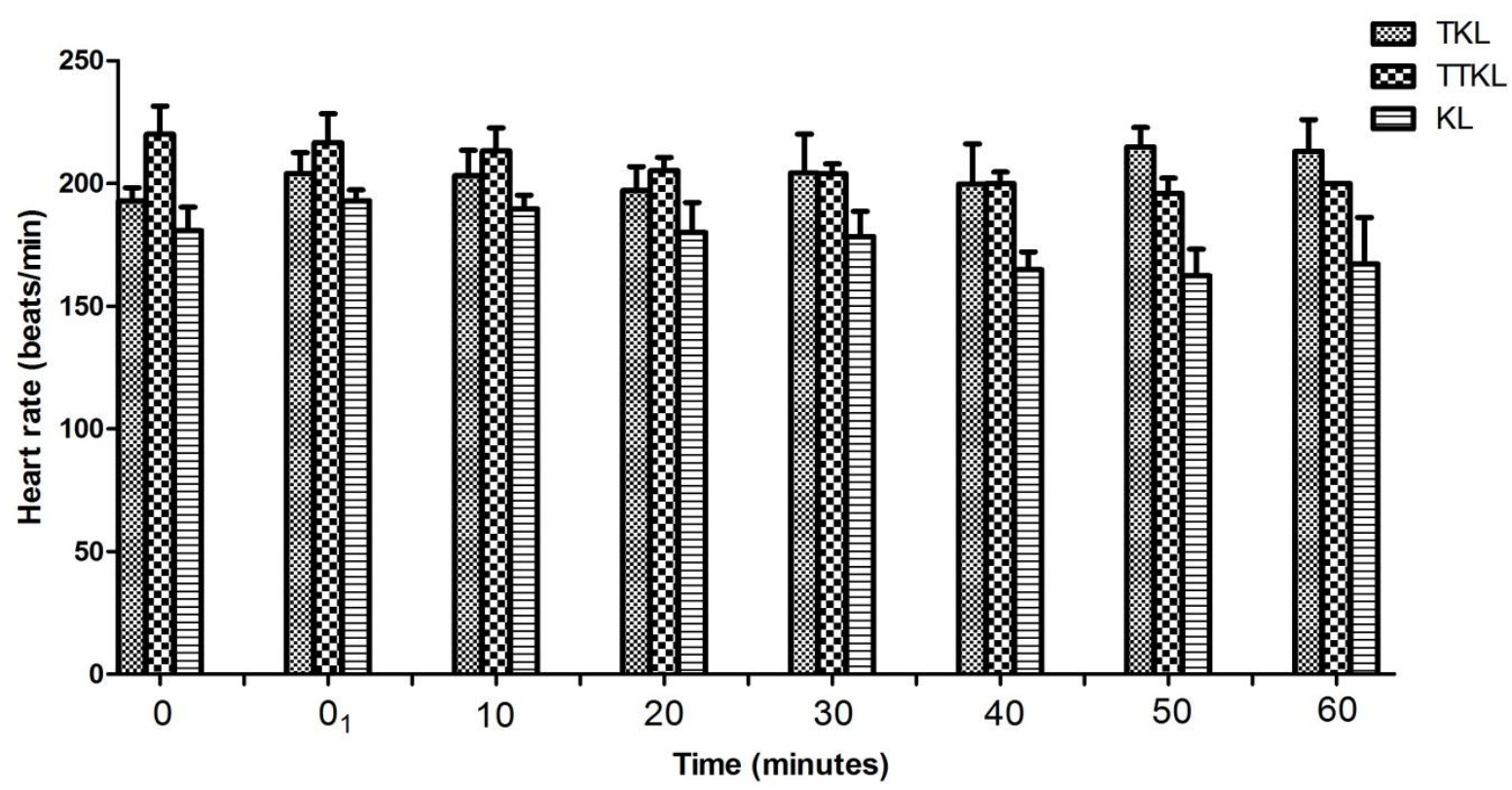

Figure 1. Heart rate response of chickens to intramuscular injections of $15 \mathrm{mg} / \mathrm{kg}$ ketamine (KL), and $10 \mathrm{mg} / \mathrm{kg}$ ketamine following either $5 \mathrm{mg} / \mathrm{kg}(\mathrm{TKL})$ or $10 \mathrm{mg} / \mathrm{kg}(\mathrm{TTKL})$ tramadol.

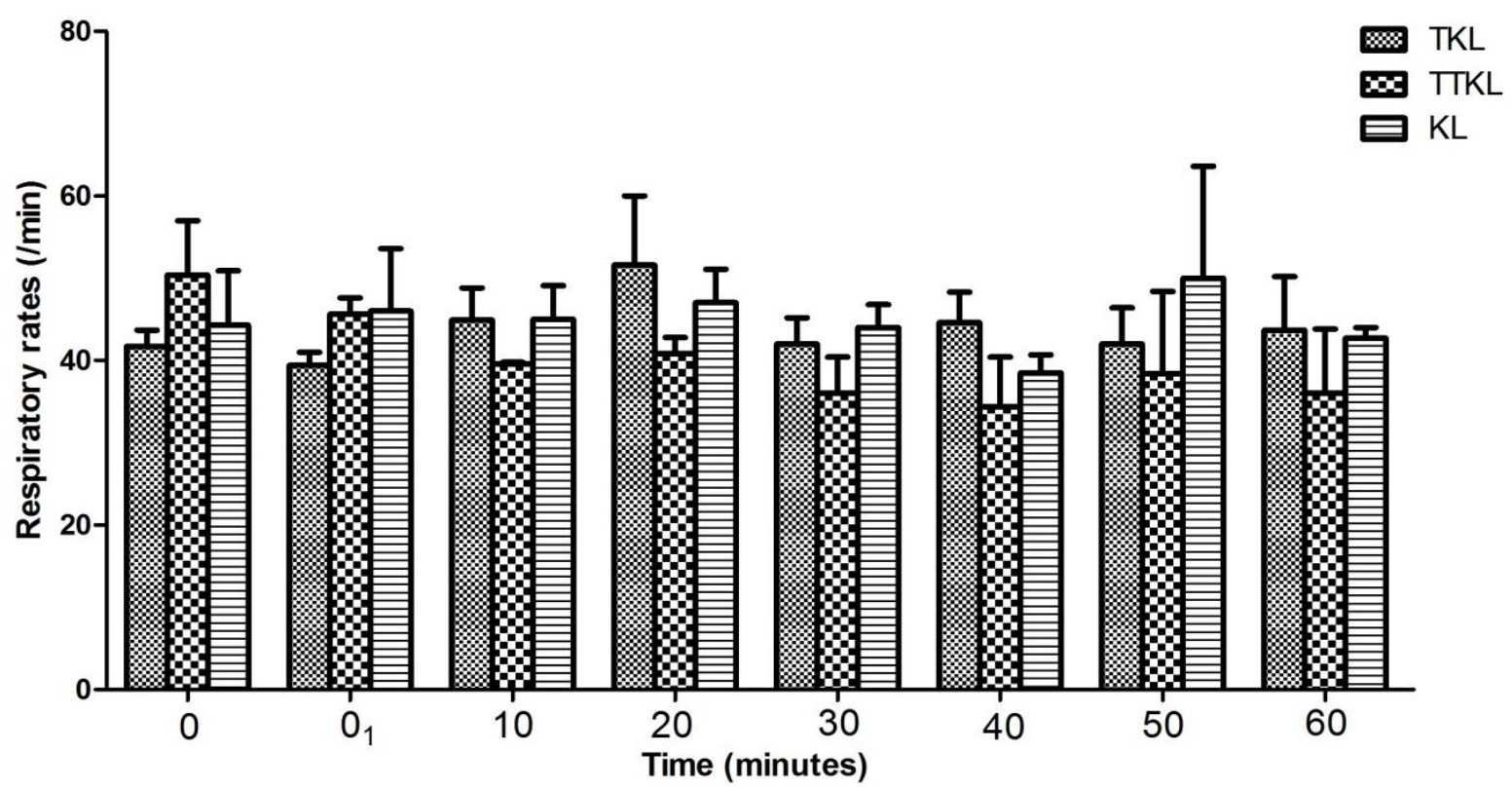

Figure 2. Respiratory rate response of chickens to intramuscular injections of $15 \mathrm{mg} / \mathrm{kg}$ ketamine (KL) and $10 \mathrm{mg} / \mathrm{kg}$ ketamine following either $5 \mathrm{mg} / \mathrm{kg}(\mathrm{TKL})$ or $10 \mathrm{mg} / \mathrm{kg}(\mathrm{TTKL})$ tramadol

as more domesticated chicken, ducks, geese and caged birds that serve for companionship for elderly people (Hall et al., 2001). The need for caecectomy (Maiti et al., 2006; Eyarefe and Oguntoye, 2012) and caponization (Mahmud et al., 2013) is also required for further injectable anaesthetic studies recently. In our previous study, $5 \%$ ketamine $(15 \mathrm{mg} / \mathrm{kg})$ alone with incision site lignocaine infiltration provided chemical restraint with prolonged recovery period. A lower dose of ketamine (10 $\mathrm{mg} / \mathrm{kg}$ ) combined with $5 \mathrm{mg} / \mathrm{kg}$ and $10 \mathrm{mg} / \mathrm{kg}$ of tramadol provided adequate chemical restraint with better analgesia which supported bowel manipulation in both the TTKL and TKL groups.

Although the onset of drug action was most rapid in the 


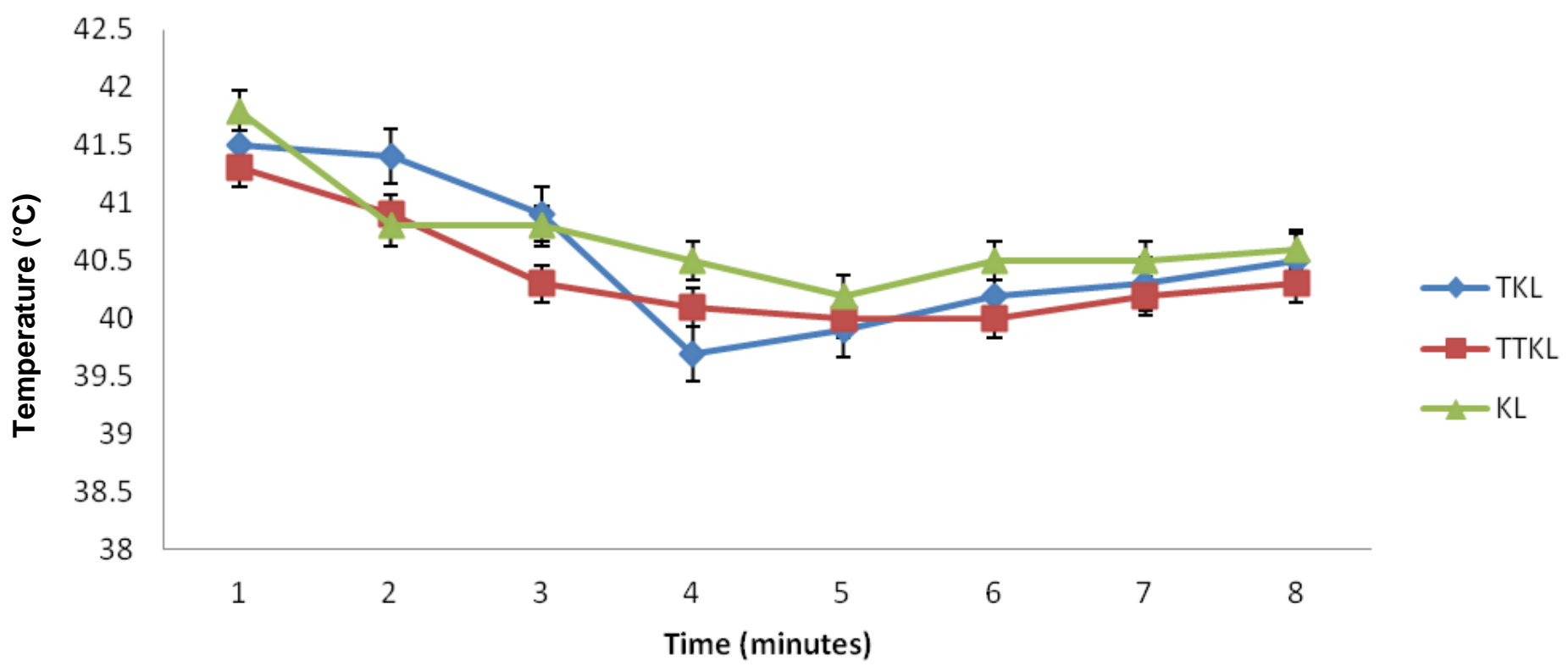

Figure 3. Cloacal temperature of chickens after intramuscular injections of $15 \mathrm{mg} / \mathrm{kg}$ ketamine $(\mathrm{KL})$, and $10 \mathrm{mg} / \mathrm{kg} \mathrm{ketamine} \mathrm{following} \mathrm{either}$ $5 \mathrm{mg} / \mathrm{kg}(\mathrm{TKL})$ or $10 \mathrm{mg} / \mathrm{kg}(\mathrm{TTKL})$ tramadol.

Table 2. Cost and analysis of anesthetic protocol for each group.

\begin{tabular}{|c|c|c|c|c|c|c|}
\hline $\begin{array}{l}\text { Drugs and anesthetic } \\
\text { groups }\end{array}$ & Ketamine & Tramadol & Lignocaine & $\mathrm{KL}$ & TKL & TTKL \\
\hline $\begin{array}{l}\text { Drug presentation in } \\
\mathrm{mg} / \mathrm{ml}\end{array}$ & $500 \mathrm{mg}$ in a $10 \mathrm{ml}$ bottle & $100 \mathrm{mg}$ in a $2 \mathrm{ml}$ ampoule & $\begin{array}{c}1000 \mathrm{mg} \text { in a } 50 \\
\mathrm{ml} \text { ampoule }\end{array}$ & - & - & - \\
\hline $\begin{array}{l}\text { Cost of drug per } \\
\text { presentation (Naira) }\end{array}$ & $\# 600$ (2.7 USD) & $\# 50$ (0.27USD) & \#170 (0.77 USD) & - & - & - \\
\hline $\begin{array}{l}\text { Cost of drug per weight of } \\
\text { bird }(\mathrm{kg})\end{array}$ & $\begin{array}{l}\text { 1) } 15 \mathrm{mg} \text { ( } \$ 18 ; 0.08 \mathrm{USD}) \\
\text { 2) } 10 \mathrm{mg} \text { ( } \$ 12 ; 0.05 \text { USD) }\end{array}$ & $\begin{array}{l}\text { 1) } 10 \mathrm{mg}(\$ 5 ; 0.02 \text { USD) } \\
\text { 2) } 5 \mathrm{mg}(\$ 2.50 ; 0.01 \text { USD) }\end{array}$ & $\# 6.80$ (0.03USD) & $\begin{array}{c}\text { \#24.80 } \\
\text { (0.11 USD) }\end{array}$ & $\begin{array}{c}\text { \#21.30 } \\
\text { (0.10 USD) }\end{array}$ & $\begin{array}{c}\text { N23.80 } \\
(0.11 \text { USD) }\end{array}$ \\
\hline $\begin{array}{l}\text { Total cost per protocol per } \\
\text { bird(mean weight } 1.43 \mathrm{~kg} \text { ) }\end{array}$ & - & - & - & $\begin{array}{c}\text { *35.46 } \\
\text { (0.16 USD) }\end{array}$ & $\begin{array}{c}\# 30.46 \\
(0.14 \text { USD) }\end{array}$ & $\begin{array}{c}\text { \#34.03 } \\
\text { (0.16 USD) }\end{array}$ \\
\hline
\end{tabular}

\#- Naira (Nigerian currency); USD- United States Dollar.

$\mathrm{KL}$ group (Table 1), the duration of recumbency was prolonged as compared to TKL and TTKL. Quick recovery from anaesthesia is desirable in birds because prolong duration of recumbency and consequent starvation could precipitate fatal hypoglycemia and ketosis associated with their high metabolic rate (Forbes, 1999; Hall et al., 2001).

The heart rates of the chickens in the three treatment groups remained fairly constant throughout the anaesthetic period with slight decrease from base line values only in the $\mathrm{KL}$ group. Studies have shown that heart rates in birds may not change considerably from normal value after initial incisional responses (Hall et al.,
2001). The fall in heart rate in the $K L$ group is contrary to the behavior of ketamine in mammals in which case the drug is known to cause tachycardia (Ajadi et al., 2008). Salerno and van Tienhoven (1976) reported a dose dependent fall in heart rates following ketamine administration in chickens although higher dosages (30$120 \mathrm{mg}$ ) were investigated.

The trend in respiratory rate for the three groups was $\mathrm{KL}>\mathrm{TKL}>\mathrm{TTKL}$. The lower but none significant respiratory rate of the birds in the TKL and TTKL groups may be associated with opiate characteristic of tramadol (Hui-Chen et al., 2004); although, tramadol is known to produce less respiratory depression when compared with 


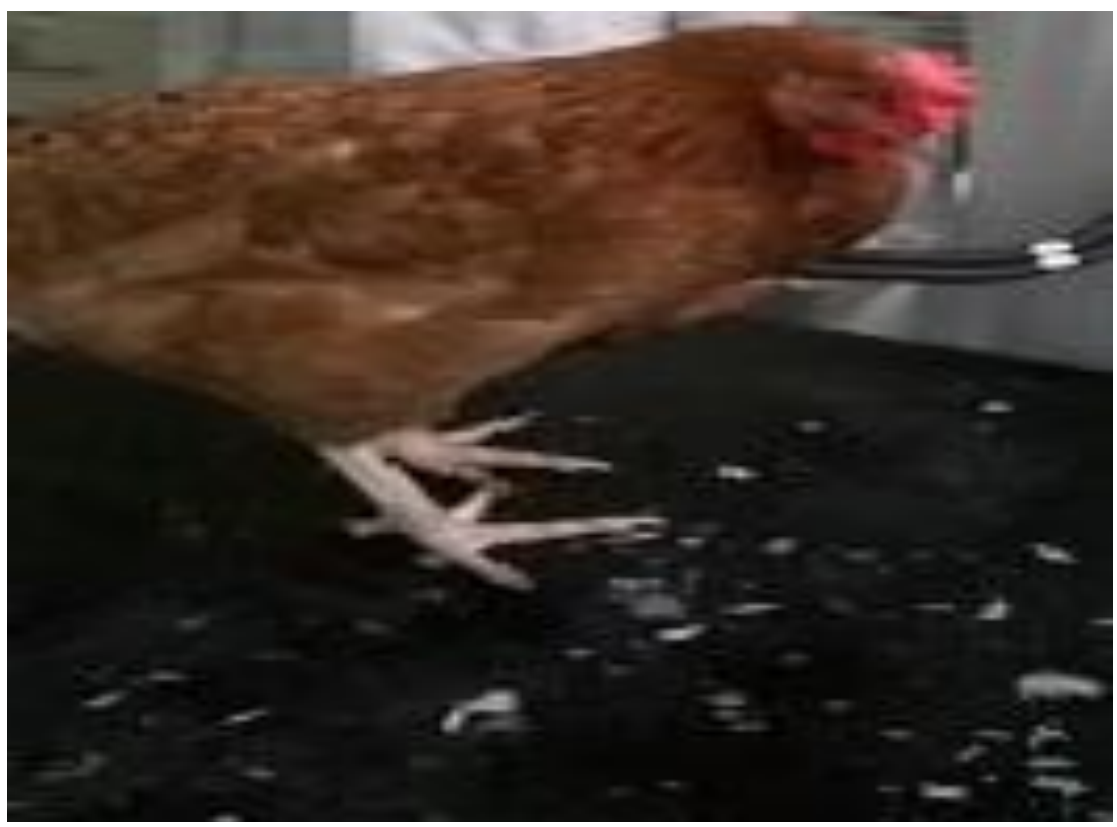

Plate 1. A chicken before injection of the anaesthetic drugs.

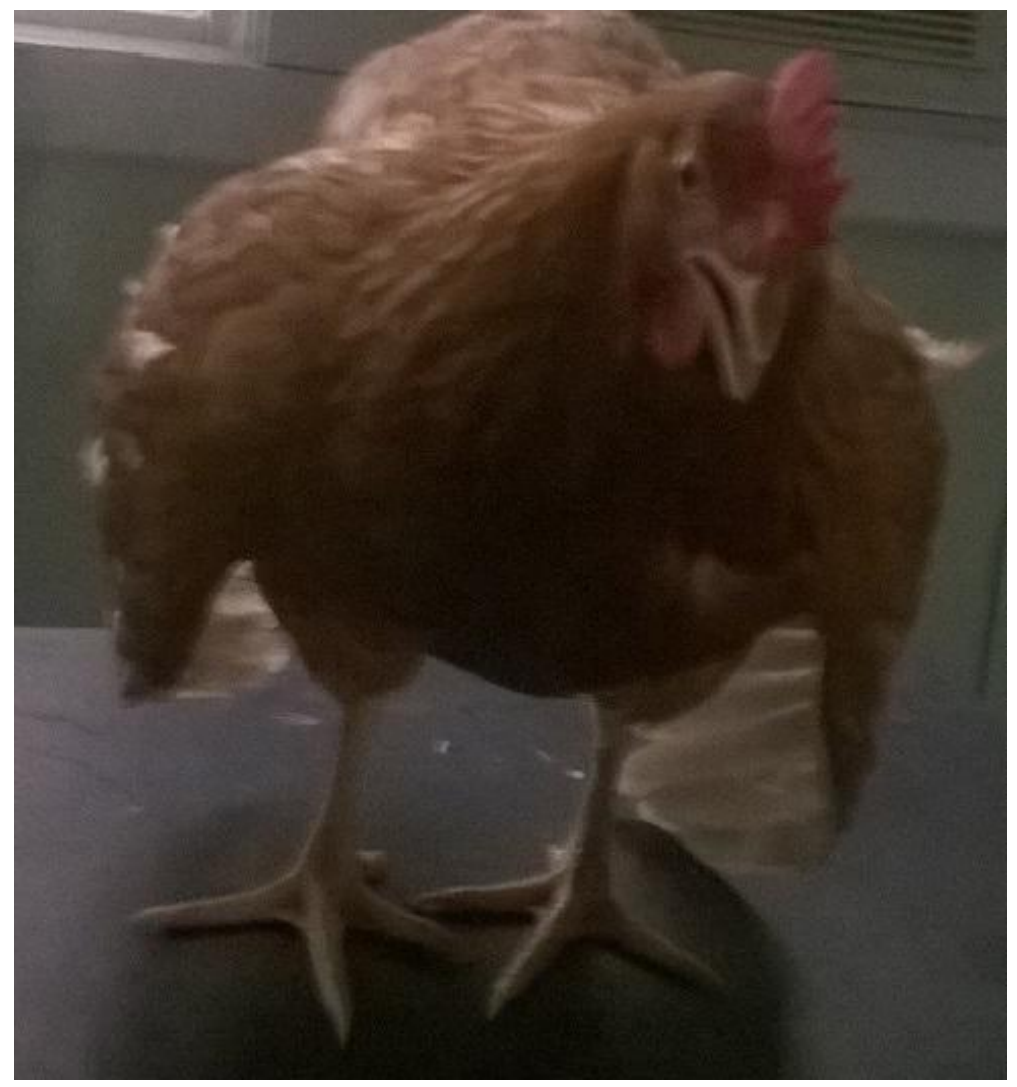

Plate 2. A chicken following onset of drug action.

other opiates (Hui-Chen et al., 2004). Birds under tramadol must have felt less pain through little or no sympathetic response resulting in a lower respiratory rate. Severe respiratory depression which may lead to 


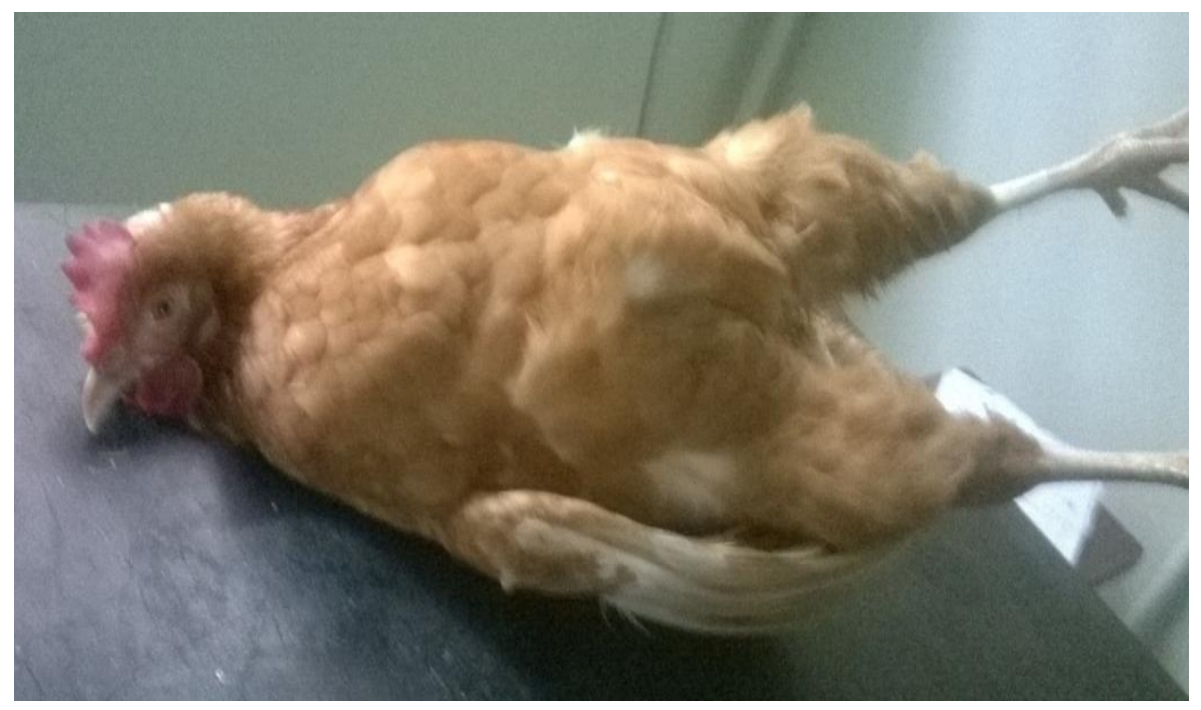

Plate 3. A chicken on lateral recumbency following loss of righting reflex

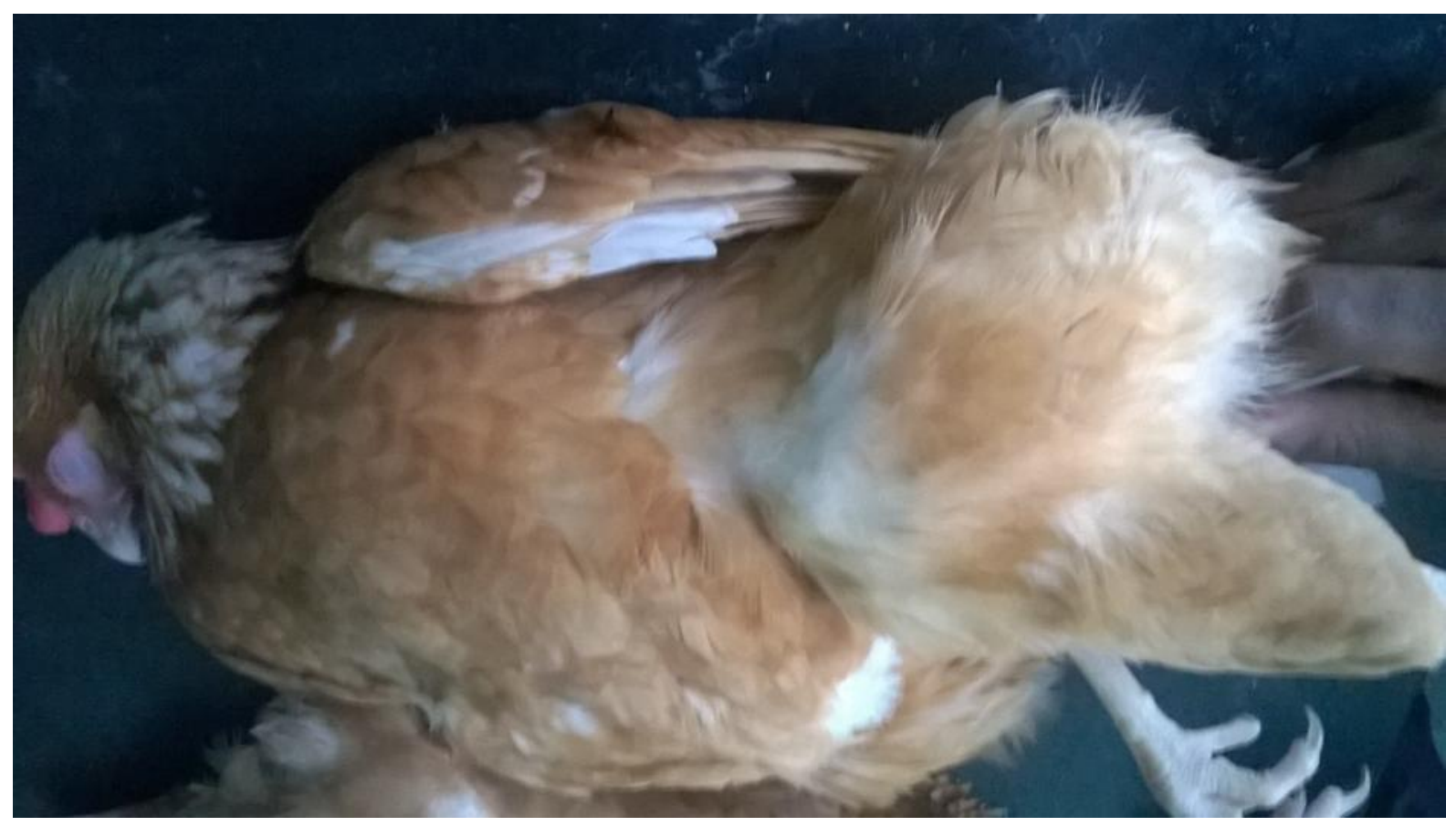

Plate 4. Chicken under ketamine-tramadol anaesthesia.

respiratory arrest was not observed in these birds (Gunkel and Lafortune, 2005).

Hypothermia is one of the most common complications of anaesthesia in birds (Boedeker et al., 2005; Nevarez, 2005). The variation in temperature of the birds under anaesthetic influence was not too pronounced when compared with their preanaesthetic values. An expected gradual insignificant $(p>0.05)$ fall in temperature was observed in all the groups, especially in the TKL group, but the temperature gradually rose to near baseline values (Flecknell, 2009). Hypothermia could be detrimental in birds as in mammals, and may trigger adverse effects of low basal metabolic rate such as poor drug metabolism and prolong recovery (Sinn, 1994; Pottie et al., 2007). Birds often lose heat through air exchange at the body surface (convection), differential between body and environment (radiation) contact with a colder surface (conduction), as well as, evaporation from 
lungs and skin. This may warrant the use of heating pads and forced air warmers for body temperature regulation (Gunkel and Lafortune, 2005). However, these measures were not, employed for the birds under investigation, except that work table surface was cushion padded to reduce heat conduction.

The cost of anaesthetic protocols in this study is worthy of note. Lack of facilities for inhalatory anaesthetic protocols and lower cost of injectable anaesthesia are usually the main considerations behind the choice of the latter in poor resource settings of African and Asian countries. The cost of the current studied protocols is considerably low and affordable when compared with inhalatory anaesthesia (Table 2).

\section{Conclusions}

In the absence of inhalatory anaesthesia, $10 \mathrm{mg} / \mathrm{kg}$ ketamine combined with tramadol ( 5 to $10 \mathrm{mg} / \mathrm{kg}$ ) and lignocaine infiltration may be a preferred for nonprotracted surgical procedures in chickens.

\section{Conflict of Interests}

The authors have not declared any conflict of interests.

\section{ACKNOWLEDGEMENT}

The authors acknowledge Dr. Afolabi J. M. for assistance in editing the manuscript.

\section{REFERENCES}

Ajadi RA, Olusa TA, Smith OF, Ajibola ES, Adeleye OE, Adenubi OT, Makinde FA (2009). Tramadol improved the efficacy of ketamine-xylazine anaesthesia in young pigs. Vet. Anaesth. Analg. 36:562-566.

Ajadi RA, Smith OF, Makinde AFM, Adeleye OE (2008). Increasing ketamine dose enhances the anaesthetic properties of ketamine-xylazine-midazolam combination in growing pigs. J. S. Afr. Vet. Assoc. 79(4):205-207.

Black PA, Cox SK, Macek M, Tieber A, Junge RE (2010). Pharmacokinetics of Tramadol Hydrochloride and its Metabolite O-Desmethyltramadol in Peafowl (Parvo cristatus) J. Zoo Wildl. Med. 41(4):671-676.

Boedeker NC, Carpenter JW, Mason DE (2005). Comparison of body temperature of pigeons (Columba livia) anesthetized by three different anesthetic delivery systems. J. Avian Med. Surg. 19:1-6.

Borer-Weir K (2014). Analgesia. In: Veterinary Anaesthesia $11^{\text {th }}$ edition. Hall LW, Clarke KW, Trim CM. Philadelphia. WB Saunders Co. pp. 102-126.

Curro TG (1998). Anesthesia of pet birds. Semin. Avian Exotic Pet. Med. 7:10-21.

Divers SJ (2014). Anaesthesia of zoological species (exotic pets, zoo, aquatic, and wild animals). In: Veterinary Anaesthesia $11^{\text {th }}$ edition. Hall LW, Clarke KW, Trim CM. Philadelphia. WB Saunders Co. pp. 535-566.
Edling TM (2006). Updates in Anesthesia and Monitoring. In: Clinical Avian Medicine. Harrison GJ, Lightfoot TL. Spinx Publishing, Lake Worth, FL USA.

Egger CM, Souza MJ, Greenacre CB, Cox SK, Rohrbach BW (2009). Effect of intravenous administration of tramadol hydrochloride on the minimum alveolar concentration of isoflurane in rabbits. Am. J. Vet. Res.70:945-949

Eyarefe OD, Oguntoye CO (2012). A Randomized Trial of LowDose Ketamine and Lignocaine Infiltration for LaparoCaecectomy in Layer Chickens. Int. J. Anim. Vet. Adv. 4(4):252255.

Flecknell PA (2009). Anaesthesia of Common Laboratory Species: Special Considerations in Laboratory Animal Anaesthesia Academic Press, San Diego, USA. pp. 181-273.

Forbes NA (1999). Birds. In: BSAVA Manual of Small Animal Anaesthesia and Analgesia. 2nd edition. Seymour C, Gleed R. Cheltenham, UK BSAVA. pp. 283-293

Franchetti DR, Klide AM (1978). Restraint and anesthesia. In: Zoo and Wild Animal Medicine. Fowler ME. Philadelphia. WB Saunders Co. pp. 359-364.

Gandomani MJ, Tamadon A, Mehdizadeh A, Attaran HR (2009). Comparison of different ketamine-xylazine combinations for prolonged anaesthesia in budgerigars (Melopsittacus undulatus). Vet. Scan 4(1):34.

Girling SJ (2009). Avian Anaesthesia. In: Anaesthesia for Veterinary Nurses $2^{\text {nd }}$ edition. Welsh E. Blackwell Publishing, Oxford, pp. 336-353.

Gunkel C, Lafortune M (2005). Current techniques in avian anesthesia. Semin. Avian Exotic Pet Med. 14:263-276.

Hall LW, Clarke KW, Trim CM (2001). Anaesthesia of birds, laboratory animals and wild animals. In: Veterinary Anaesthesia. Hall LW, Clarke KW, Trim CM. Philadelphia. WB Saunders Co; 2001. pp. 463-479.

Hawkins MG, Paul-Murphy JR (2011). Avian analgesia. Vet. Clin. North Am. Exot. Anim. Pract. 14(1):61-80.

Hui-Chen L, Yang Y, Na W, Ming D, Jian-Fang L, Hong-Yuan X (2004). Pharmacokinetics of the enantiomers of transtramadol and its active metabolite, trans-O-demethyltramadol, in healthy male and female Chinese volunteers. Chirality 16:112-118.

Javdani M, Ghashghaei A, Nikousefat Z (2012). Evaluation of anesthetic and analgesic effect of ketamine in combination of tramadol, midazolam, hyoscine, and atropine in broiler chickens. J. Vet. Med. 6(1):11-17

Javdani M, Nikousefat Z, Ghashghaei A, Hashemnia M (2014). Efficacy of ketamine in combination with four common analgesics on some hematological factors of broiler chickens. Int. J. Livest. Res. 4(2):1-9

Lamont LA, Tranquilli WJ, Mathews KA (2000). Adjunctive analgesic therapy. Vet. Clin. North Am. Small Anim. Pract. 30:805-813.

Ludders JW (2015). Birds. In: Lumb and Jones Veterinary anaesthesia and analgesia $4^{\text {th }}$ edition. Tranquilli WJ, Thurmon JC and Green KA. Blackwell lowa, USA. pp. 800-813.

Ludders JW, Mathews NS (2007). Birds. In: Lumb and Jones Veterinary anaesthesia and analgesia $4^{\text {th }}$ edition. Tranquilli $\mathrm{WJ}$, Thurmon JC and Green KA. Blackwell lowa, USA. P. 841-868.

Mahmud MA, Shaba P, Gana J, Yisa HY, Ndagimba R (2013). Effects of surgical caponisation on growth, carcass and some haematological parameters in cockerel chickens. Sok. J. Vet. Sci. 11:57-62.

Maiti SK, Tiwary R, Vasan P, Dutta A (2006). Xylazine, diazepam and midazolam premedicated ketamine anaesthesia in white Leghorn cockerels for typhlectomy J. S. Afr. Vet. Assoc. $77(1): 12-8$.

Nevarez JG (2005). Monitoring during avian and exotic pet anesthesia. Semin. Avian Exotic Pet Med. 14:277-283.

Paul-Murphy J, Fialkowski J (2001). Injectable Anesthesia and Analgesia of Birds. In: Recent Advances in Veterinary Anesthesia and Analgesia: Companion Animals. Gleed RD, Ludders JW. 
International Veterinary Information Service (www.ivis.org), Ithaca, New York, USA. (5-Aug-2001)

Pottie RG, Dart CM, Perkins NR, Hodgson DR (2007). Effect of hypothermia on recovery from general anaesthesia in the dog. Aust. Vet. J. 85:158-162.

Salerno A, van Tienhoven A (1976). Comparative biochemistry and physiology. C: Comparative Pharmacol. 55(1):69-75

Sawyer DC, Rech RH, Durham RA (1993). Does ketamine provide adequate visceral analgesia when used alone or in combination with acepromazine, diazepam, or butorphanol in cats? J. Am. Anim. Hosp. Assoc. 29:257-263.

Sinn LC (1994). Anesthesiology. In: Avian Medicine: Principles and Application. BW Ritchie, GJ Harrison, LR Harrison. Wingers Publishing, Lake Worth, Florida, USA. pp. 1067-1080.
Souza MJ, Guzman DS, Paul-Murphy JR, Cox SK (2009). Pharmacokinetics after oral and intravenous administration of a single dose of tramadol hydrochloride to Hispaniolan Amazon parrots (Amazona ventralis) J. Avian Med. Surg. 23(4):247-252.

Souza MJ, Guzman DS, Paul-Murphy JR, Cox SK (2012). Pharmacokinetics after oral and intravenous administration of a single dose of tramadol hydrochloride to Hispaniolan Amazon parrots (Amazona ventralis) Am. J. Vet. Res. 73(8):1142-1147.

Uzma F, Durrani M, Arif K, Saleem Ahmad S (2008). Comparative efficacy (sedative and anaesthetic) of detomidine, ketamine and detomidine-ketamine cocktail in pigeons (Columba livia). Pak. Vet. J. 28(3):115-118. 